\title{
ATELIÊ DO IPREDE: EXPERIÊNCIA E EDUCAÇÃO ESTÉTICA NO TERCEIRO SETOR.
}

SILVA, C.V. ${ }^{1}$; GOLDBERG, L.G. ${ }^{2}$; PINTO, P.A.H.S. ${ }^{3} \&$ LARRIPA, T.Q.B. ${ }^{4}$

${ }^{1}$ Doutora em Educação, Professora e Diretora Teatral (FACED/UFC). E-mail: carolinavieira.teatro@ gmail.com ; ${ }^{2}$ Doutora em Educação Brasileira pela Universidade Federal do Ceará (UFC). E-mail: lugoldberg@ @otmail.com ; ${ }^{3}$ Doutor em Artes Cênicas pelo Programa de PósGraduação em Artes Cênicas da Universidade Federal da Bahia (UFB). E-mail: phteatro@ hotmail.com; ${ }^{4}$ Especialista em Metodologia do Ensino na Educação Superior (UNINTER - 2016). E-mail: tlarripa@gmail.com

Artigo submetido em 02/09/2018

\section{RESUMO}

Este relato de experiência tem como objeto o projeto de extensão do Instituto de Cultura e Arte da Universidade Federal do Ceará, Ateliê do Iprede: experiência e educação estética no terceiro setor. Tal ação de extensão tem como objetivo principal colaborar com o Iprede através da elaboração de um modus operandi que privilegie a experiência estética e singular no campo pedagógico na primeira infância. Neste relato, tratamos de apesentar o local de atuação do projeto, o Instituto da Primeira Infância (Iprede); em seguida, nortear os objetivos do projeto de extensão e as principais ações desenvolvidas, bem como seus diálogos teóricometodológicos. Salientamos, também, o Curso de Extensão e o Simpósio, ambos denominados de Arte, Cultura e Primeira Infância, que se somaram à esta ação de extensão validando seu compromisso com a formação continuada. Ressaltamos as pesquisas acadêmicas que possuem o Ateliê do Iprede como espaço de investigação e extensão e, também, algumas estratégicas utilizadas para a curricularização da extensão já engendradas através deste que projeto. Este projeto de extensão apresentou-se salutar nos âmbitos do fomento da pesquisa e da investigação de metodologias de ensino; ao mesmo tempo vem se tornando espaço de formação continuada para profissionais da área da saúde, da educação e das artes e, por fim, se apresenta como espaço de produção e democratização de bens culturais para a primeira infância.

PALAVRAS-CHAVE: Arte. Educação. Experiência Estética. Primeira Infância.

\section{ATELIÊ DO IPREDE: EXPERIENCE AND ESTHETIC EDUCATION IN THE THIRD SECTOR}

\begin{abstract}
The aim of this experience report is the extension project of the Institute of Culture and Art of the Federal University of Ceará, Ateliê do Iprede: experience and aesthetic education in the third sector. The main objective of this extension action is to collaborate with the Iprede through the elaboration of a modus operandi that privileges the esthetical and singular experience (DEWEY, 2010) in the pedagogical field (LARROSA, 2014) in the early childhood. In this report we present the project's location, the Early Childhood Institute (Iprede); then we guide the objectives of the extension project and the main actions developed, as well as their theoretical-methodological dialogues. We also emphasize the Extension Course and the Symposium,
\end{abstract}

validating their commitment to continuing both called Art, Culture and Early Childhood, which were added to this extension action,education. We emphasize the academic researches that have the Atelie do Iprede as a space for research and extension. We also highlight some strategies used to introduce de extension activities in the academic structure of the extension already generated through this project. This extension project proved to be wholesome in the areas of research promotion and research methodologies; at the same time, it has become a space for continuing education for professionals in the health, education and arts sectors and, finally, it presents itself as a space for the production and democratization of cultural goods for early childhood.

KEYWORDS: Arts. Edication. Aesthetic Experience. Early Childhood. 


\section{INTRODUÇÃO}

O Instituto da Primeira Infância (Iprede), fundado em 1986, tinha como foco principal de atuação a desnutrição infantil. Atualmente, a instituição empreende novas ações em direção ao desenvolvimento integral da criança, promovendo a inclusão sócio-produtiva das famílias e o estabelecimento de vínculos. O Iprede assiste a uma média de 1.300 crianças e seus familiares em situação de vulnerabilidade social da capital do estado do Ceará (Fortaleza), região metropolitana e de municípios próximos.

Com uma visão holística da infância, empreendida através de projetos, programas e serviços, o Iprede é um centro de referência sobre a primeira infância. Neste sentido, uma vez que a Arte colabora para que as pessoas possam elaborar conhecimentos sensíveis e inteligíveis de forma complementar, a educação e a experiência estética tornam-se fundamentais nos processos de autoconhecimento das famílias, nas interações sensíveis com o mundo e, também, fomentam vivências geradoras de sentidos.

O Ateliê do Iprede, ação de extensão que é coordenada pela professora Autor ${ }^{1}$ e objeto deste relato de experiência, atua junto ao Setor de Acolhimento desta instituição. Este setor, conta com uma equipe multiprofissional e tem como objetivo realizar a primeira aproximação das famílias com a instituição para orientá-las quanto aos serviços prestados. Neste contexto, o Ateliê do Iprede mostra-se uma ação extensionista que atua com problema e situação identificados e que pretende oferecer às díades (mãe/filho) a oportunidade do alumbramento e da paz de espírito (MONTAGNER, 1993).

O Ateliê do Iprede é um projeto de extensão do Instituto de Cultura e Arte da Universidade Federal do Ceará que tem como objetivo principal colaborar com o Iprede através da elaboração de um modus operandi que privilegie a experiência estética e singular (DEWEY, 2010) no campo pedagógico (LARROSA, 2014) na primeira infância, tendo como local de atuação o ambiente de acolhimento desta instituição.

Um ateliê é por excelência um espaço de artesania. Em nosso caso, um local de experimentação, manipulação e produção das mais diversas linguagens artísticas. Podemos considerá-lo como um espaço propício para a experiência na medida estética; isto porque “[...] a arte é a mais efetiva forma de comunicação que existe. Por esta razão, a presença de fatores comuns ou gerais na experiência consciente é efeito de arte.” (DEWEY, 2010, 491). Acreditamos, portanto, que a proposta deste Ateliê oferece oportunidades de expressão e comunicação mediadas pelas linguagens artísticas. 
O espaço de acolhimento do Iprede já conta com ambientes preparados para receber as crianças e suas mães: sala de leitura, cineminha, espaço para desenho, pintura e brincadeiras com jogos didáticos, um pequeno palco e um parquinho. Deste modo, as ações que estão sendo direcionadas para a educação e a experiência estética partem, inicialmente, da realização de propostas de ocupação continuada e formativa, dinamizando a utilização destes espaços com atividades direcionadas para as mães e as crianças em atendimento na instituição. O Ateliê também colabora criando fluxos entre produtos artísticos (gerados na UFC ou por artistas locais que atuem de maneira voluntária) e o Iprede. Com isso, levamos ao público espetáculos cênicos e musicais, e agenciamos a ida de grupos focais a espaços culturais da cidade, sustentados por ações de mediação.

No âmbito da mediação, que é toda ação que colabora com o acesso do público às manifestações e obras artísticas, vislumbramos o acesso em dois aspectos, quais sejam: físico e simbólico (KOUDELA, 2012). Entendemos por acesso físico, as iniciativas que facilitam a ida do público a espaços de difusão de obras artísticas. Porém, acreditamos que nosso principal desafio é o acesso simbólico, ou seja, colaborar para a construção de uma capacidade de elaboração inteligível e sensível para se relacionar com os outros e consigo mesmo. Podemos afirmar que todos nós possuímos a capacidade inata de produzir e fruir Arte; logo, o acesso contínuo e mediado à produções artísticas, de vigor poético e ético, é fundamental para o desenvolvimento dos sujeitos.

Propusemos, para tanto, a criação de uma equipe multidisciplinar oriunda das licenciaturas em Teatro, Pedagogia, Música e Dança da Universidade Federal do Ceará para trabalhar de modo integrado com os profissionais do Iprede. Mesmo diante das diversas preferências estéticas e teóricas da equipe imbuída neste trabalho, as propostas artísticopedagógicas procuram estar atravessadas pelas temáticas de alumbramento e de paz de espírito trazidas como base teórico-metodológica pelo setor de acolhimento da instituição, as quais são inspiradas pelo psiquiatra e psicanalista francês Hubert Montagner.

Alumbrar significa iluminar, inspirar, maravilhar. Neste sentido, acreditamos que a Arte pode se ocupar de fomentar espaços de alumbramento, os quais sendo importantes para a formação de todo indivíduo tornam-se, ainda, essenciais para facilitar a diminuição dos níveis de estresse enfrentados pela população que vive em extrema pobreza. Ainda segundo o autor, o ambiente de aprendizado deve favorecer que a criança alcance um estado de paz de espírito (batimentos cardíacos e pressão arterial reduzida, bem como coração regulado) através do qual ela se torna mais disposta a aprender. 
Dialogamos teórica e metodologicamente, também, com os estudos sobre experiência trazidos pelo filósofo e educador Jorge Larrosa Bondia quando da sua percepção de que a experiência pertence aos fundamentos da vida e, assim,

Há algo no que fazemos e no que nos acontece, tanto nas artes como na educação, que não sabemos muito bem o que é, mas que é algo sobre o que temos vontade de falar. E de continuar falando, algo que temos vontade de pensar e continuar pensando, e algo que temos vontade de cantar, e de continuar cantando, porque justamente isso é que faz com que a educação seja educação, com a arte seja arte e, certamente, com que a vida esteja viva, ou seja, aberta a sua própria natureza. (LARROSA, 2014, p.13)

Portanto, as incursões artístico-pedagógicas do Ateliê do Iprede perpassam todas as linguagens artísticas e contam com ações das seguintes naturezas: contação de histórias, desenho, apresentação de espetáculos cênicos e musicais, experimentação com jogos dramáticos e mediação dos filmes exibidos no cineminha. Sabemos que tais abordagens artístico-pedagógicas, ainda, são bastante desafiadoras. Logo, temos:

[..] a clara convicção de que não existe apenas um caminho para o desenvolvimento do trabalho com teatro na escola e, além disso, a firme opinião de que, entre os caminhos possíveis, nenhum pode ser considerado absoluta e descontextualizadamente, melhor ou superior aos outros. (JAPIASSU, 2001, p. 22)

Ratificamos a certeza de que os caminhos para a abordagem da Arte devem seguir na direção dos propósitos da instituição que as acolhe e contribuir com os objetivos por ela já estabelecidos, buscando também ser geradora de novos horizontes.

A Arte precisa ser tratada como conhecimento e, com isso, ser incorporada ao trabalho do educador não mais de modo, exclusivamente, intuitivo. Segundo a arte-educadora Ana Mae Barbosa (2005), a falta de preparação de pessoal para ensinar artes é um problema crucial, nos levando a confundir improvisação com criatividade. Observamos que:

A falta de formação faz com que esses professores atuem movidos pela concepção de
Arte e do seu ensino, construída ao longo de suas histórias pessoais. E como,
historicamente, a maioria dos professores foi privada do acesso ao repertório cultural
da Arte, tanto na vivência de sua expressividade em atos artísticos quanto na
possibilidade de refletir sobre seus conteúdos na escola, isso gerou uma falta de
consciência sobre os sentidos que esses conteúdos e vivências artísticas podem
assumir na escola. (PONTES, 2011, p. 22).

Neste sentido, o projeto destacou-se, também, em estratégias de aproximação das referidas licenciaturas com o terceiro setor. Demos vazão às seguintes ações: acolhemos estagiários da Licenciatura em Dança; extensionalizamos duas disciplinas do curso de Teatrolicenciatura (Práticas de Encenação e Iniciativas em Teatro Educação) que foram ministras no Iprede, promovendo o contato direto com a comunidade e, por fim, acolhemos discentes voluntários que optaram por integralizar horas de atividades complementares colaborando com o Ateliê do Iprede.

Deste modo, afirmamos a colaboração deste projeto para a formação integral dos licenciandos em Artes e Pedagogia, uma vez que está sendo oferecido a eles a oportunidade de 
experimentar a observação e a regência de ações artístico-pedagógicas no terceiro setor. Com isso, os discentes podem realizar uma análise crítica da realidade; compartilhar saberes e se reconhecer como colaboradores para minimizar o quadro gerado pelas injustiças sociais em nosso país. O trabalho no terceiro setor possibilita, ainda, a ampliação da responsabilidade social dos envolvidos para além da dimensão da educação escolar. Acreditamos que o currículo de formação de professores deva se ocupar com a cidadania e, portanto, com a reflexão e a ação em questões sociais urgentes.

A experiência e a educação estética são pontos de preocupação dos currículos dos cursos de licenciatura em artes e pedagogia da Universidade Federal do Ceará. O Projeto Político Pedagógico do curso de Pedagogia (FACED-UFC), por exemplo, coloca o desenvolvimento da sensibilidade ético-estética como ponto prioritário de formação básica. Logo, encontramos no Ateliê do Iprede uma oportunidade para fomentar nossas práticas curriculares, oferecendo um espaço de atuação para os licenciandos que desejarem investir na construção de conhecimentos voltados para a primeira infância.

Uma vez que acreditamos nas práticas inter e transdisciplinares para atender as complexidades formativas do nosso tempo, o Ateliê do Iprede se configura como um laboratório para experimentações artístico-pedagógicas que integrem diversos campos do saber e, por isso, exigem formação de equipes multidisciplinares.

Tendo sido contemplado com edital da Secretaria do Trabalho e Desenvolvimento Social (STDS/CE), com o título Ateliê da Infância: experiência de cidadania e educação estética, o Ateliê do Iprede foi incorporado como ação regular do atendimento da instituição. Esta nova etapa do projeto caracterizou-se, principalmente, pelo aumento da demanda. Para tanto, selecionamos uma equipe de profissionais que receberam treinamento e formação. As atividades financiadas ocorreram de setembro de 2017 à agosto de 2018, através das seguintes ações: contação de histórias, exibição de filmes curtos, produção de desenho infantil e apresentação de espetáculos cênicos. Tais ações foram pautadas por temas transversais e, neste período, os temas selecionados foram: o medo; o que faz você feliz; palavras encantadas; bom dia todas as cores; quem sou eu; e sonhos.

As atividades eram direcionadas para grupos de aproximadamente 8 a 10 crianças com seus acompanhantes, contemplando três grupos por turno, totalizando um público de aproximadamente 600 crianças e acompanhantes por quinzena. Também iniciamos o projeto de contação de histórias para bebês e seus acompanhantes, experimentando elementos visuais e sonoros. 
O Iprede desenvolve atividades diferenciadas durante a Quinzena da Criança (mês de outubro) e a Quinzena do Natal (mês de dezembro), promovendo apresentações artísticas e entrega de presentes para as crianças atendidas. Em 2017, as apresentações que integraram tais quinzenas foram coordenadas pelo Ateliê. Ainda em parceria com o curso de Teatro-licenciatura da UFC, também foi realizada em 2018 a Mostra Teatro de Primeira, na qual foram apresentados quatro espetáculos teatrais para o público infantil, elaborados no âmbito da disciplina de Práticas de Encenação do curso de Teatro, foram eles: Quem roubou a minha luz; A Pata, a Morte e a Tulipa; A menina e o pássaro encantado; e O galinheiro de Bragança. Totalizamos 30 apresentações e recebemos uma média de público de 900 pessoas.

Como ação de culminância, foi elaborada a Exposição Ateliando no Iprede. Assim, cada espaço da instituição recebeu painéis com descrição, fotos, imagens e desenhos das crianças e das mães de cada atividade desenvolvida pelo projeto Ateliê do Iprede ao longo desses 12 meses de ações. Neste período, o Ateliê do Iprede esteve presente na instituição de segunda à sexta de 08 às 15h; apresentou 30 obras cênico-musicais; exibiu 07 vídeos no cineminha, realizou 02 projetos de leitura e 12 oficinas de desenho e pintura.

Tendo observado, também, a importância de qualificar os profissionais que atuam com a primeira infância, propusemos a criação de um curso de extensão em Arte, Cultura e Primeira Infância, tomando-as como áreas preponderantes para o desenvolvimento humano.

O curso iniciado em fevereiro de 2018 conta com dez encontros temáticos, com duração de duas horas, realizados uma sexta-feira por mês na sede da instituição. A abordagem metodológica de cada encontro fica a critério do palestrante e as diretrizes pedagógicas que norteiam este curso de extensão contemplam a complexidade das áreas de saber abordadas; sempre com uma visão educativa crítica, calcada na atualidade e em uma visão omnilateral do desenvolvimento humano.

O curso de extensão em Arte, Cultura e Primeira Infância acontece no Canal PI (canal primeira infância) na sede do Iprede e tem previsão de término para dezembro do mesmo ano. Iniciamos este curso com uma vivência em contação de história e desenho (tal qual vem sendo realizado pela equipe do Ateliê do Iprede para as crianças e seus acompanhantes). O objetivo foi vivenciar o fruir e o fazer artísticos para compreender, corporeamente, o sentido da arte na dimensão da formação humana. Iniciamos o curso com 70 pessoas matriculadas, das quais 40 seguem regularmente presentes frequentando as atividades. Importante salientar que o público é formado por professores, médicos, psicólogos, assistentes sociais e estudantes; não obstante contamos com um amplo número de integrantes do quadro de profissionais do Iprede. 
Ainda neste contexto, propusemos a realização de um simpósio, sob o mesmo tema: Arte, Cultura e Primeira Infância. O simpósio apresentou-se como uma oportunidade de debater temas relevantes para o desenvolvimento na primeira infância através de um olhar multidisciplinar, proporcionando o encontro singular em duas mesas redondas de um médico e uma artista; e duas arte-educadoras e uma psicóloga. Oportunizamos, portanto, um espaço/tempo para conversar sobre a experiência no sentido estético através de um olhar cuidadoso com a primeira infância, bem como para compartilharmos projetos, ideias, e sonhos sobre o fazer e o fruir artísticos com as crianças pequenas e a importância da participação ativa de seus cuidadores.

Destacamos, também, a importância que o Ateliê do Iprede deposita no fomento das pesquisas científicas, tendo em vista os debates emergentes sobre a necessidade de um investimento saudável em todas as dimensões humanas como condição basilar para o desenvolvimento do ser humano.

O Ateliê conta com pesquisadores do Diafhna - Grupo de Pesquisa Dialogicidade, Formação Humana e Narrativas - registrado no Diretório de Grupos de Pesquisa do Conselho Nacional de Desenvolvimento Científico e Tecnológico (CNPq). Este grupo está inserido na linha de Pesquisa Movimentos Sociais, Educação Popular e Escola; e está, também, associado ao Projeto de Extensão Rede de Educadores em Defesa dos Direitos da Criança e do Adolescente (Reeduca); bem com a este projeto de extensão em questão neste relato.

Do mesmo modo, o Ateliê também se fortalece como campo de atuação de duas pesquisas científicas qualitativas, são elas: Ateliê do Iprede: experiência estética na primeira infância (CNPQ - PIBIC 2018/2019 - Edital No 2/2018); e Ateliê do Iprede: arte e experiência estética com crianças em situação de vulnerabilidade social (pesquisa em nível de mestrado PPGE/UFC), a serem desenvolvidas no Iprede.

O primeiro projeto acima citado é um projeto de Iniciação Científica submetido e aprovado pela Pró-Reitoria de Pesquisa e Pós-Graduação- UFC, sob a condução da professora Autor $^{2}$ Traz como principal objetivo pesquisar a contribuição do projeto de extensão Ateliê do Iprede: educação e experiência estética no terceiro setor para a primeira infância no Setor de Acolhimento do Instituto da Primeira Infância (Iprede). É a partir do trabalho que vem sendo desenvolvido na instituição que as ações de pesquisa foram pensadas e estão sendo realizadas como uma forma de entender, avaliar e refletir teoricamente - à luz de variados autores da área da arte, da educação e de áreas afins - a contribuição do Ateliê junto às crianças e mães e/ou cuidadores que são atendidas quinzenalmente. 
A maior inquietação da referida pesquisa é produzir conhecimento sobre o que podemos aprender dessa experiência estética. Refletir sobre a verdadeira contribuição da Arte para a vida de crianças em situação de vulnerabilidade social na primeira infância, a partir do lugar da contação de histórias e do desenho no desenvolvimento infantil e no fortalecimento do vínculo da diáde mãe/filho(a).

Este projeto de pesquisa teve início em agosto de 2018, sendo contemplado com uma bolsa de Iniciação Científica da UFC. Algumas atividades da pesquisa já vinham sendo realizadas com a equipe de trabalho do Ateliê interessada em aprofundar aspectos teóricos e refletir sobre as suas atividades. Esperamos em um ano, tempo total previsto para este projeto, responder aos objetivos previstos e assim, compreender com mais propriedade e profundidade a importância e a relevância da arte e da experiência estética para a primeira infância, a partir da atuação do Ateliê do Iprede.

Já o segundo projeto de pesquisa, denominado Ateliê do Iprede: arte e experiência estética com crianças em situação de vulnerabilidade social é uma pesquisa em nível de mestrado que está sendo desenvolvida por Autor ${ }^{4}$ no âmbito da Pós-Graduação em Educação da Faculdade de Educação da UFC.

Tal pesquisa se vincula com os projetos de pesquisa e extensão supracitados e busca expor e refletir sobre as contribuições da Arte para as crianças e famílias atendidas pelo Iprede. Também iniciada em agosto de 2018, a mestranda ainda se encontra em fase inicial de revisão de material bibliográfico. A pesquisa tem como metodologia proposta a pesquisa-ação, utilizando-se de diário de itinerância e entrevistas semi-estruturadas com as crianças, as mães e os profissionais da instituição, a fim de compreender os efeitos das atividades realizadas para essas crianças e mães atendidas.

No âmbito da arte teatral, o Ateliê acolhe o desenvolvimento das atividades do Garapa (Grupo de Aprimoramento, Reciclagem, Artesania e Pesquisa da Atuação). Este grupo de pesquisa surge pela prática da atuação do professor Autor ${ }^{3}$ nas disciplinas do setor de estudo de Interpretação Teatral. Deste modo, os exercícios cênicos, as montagens teatrais e o trabalho constante em salas de ensaio, foram cunhando a possibilidade do surgimento deste grupo de pesquisa que se fundamenta no/pelo e através do próprio processo teatral.

No Garapa, entende-se que a pesquisa acadêmica se constitui a partir de um pleno e potente mergulho dos sujeitos envolvidos (Grupo) no objeto (Pesquisa da Atuação). Tal condição é primordial para que se alcance as metas e reais percepções que os indicadores possam traduzir (Aprimoramento, Reciclagem e Artesania). O Garapa é um grupo de pesquisa 
da atuação, seu trabalho é, portanto, coletivo e ético; e se propõe à investigação do trabalho do ator, fundamentado na condição necessária da prática teatral e todos os fatores que contribuem para o seu crescimento.

Em parceria com as atividades do Ateliê do Iprede, o Garapa decidiu inaugurar um novo braço em sua pesquisa da atuação: assim surgia o Garapinha, como um recorte da interpretação pensada para a infância. As experiências do condutor do grupo no teatro infantil, bem como sua ação na coordenação de eventos do Ateliê, foram preponderantes para tal desenvolvimento.

Como célula inicial de trabalho, está em processo de montagem o espetáculo infantil Francisco Pequeno. O espetáculo é pensado prioritariamente para crianças de 0 a 3 anos, o que não impede a sua fruição por crianças maiores e adultos. Esta investigação cênica abre as portas para uma pesquisa de linguagem específica para o público desta faixa etária. Em nosso processo, estamos atentos não somente à dramaturgia, mas também à sinestesia e à recepção destes fruidores em potencial.

Assim finalizamos este relato de experiência: apresentando o Ateliê do Iprede desde o seu nascedouro, destacando suas diversas atuações na extensão, ensino e pesquisa. Diante do exposto, acreditamos que a articulação de atividades e disciplinas da graduação com a extensão, bem como o conjunto de ações engendradas pelas pesquisas acadêmicas têm se mostrado imprescindíveis para revisão de nossas práticas artísticas e de docência. Em igual relevância, seguimos com o objetivo do desenvolvimento de saberes e fazeres que contribuam com a Arte e a primeira infância.

Em consonância com o Iprede, que já é um espaço de geração e disseminação de conhecimentos técnico-científicos, desejamos que o Ateliê do Iprede se constitua como um espaço de inovação em ensino, pesquisa e extensão na pedagogia e mediação da Arte para as crianças em primeira infância. Logo, pretendemos continuar com o desenvolvimento de ações junto à comunidade acadêmica e outros setores da sociedade, incentivando e colaborando com a melhoria da pesquisa em arte-educação. Para tanto, privilegiamos um trabalho em direção ao fomento das relações entre o conhecimento artístico-científico e as demandas sociais.

Nossa visão é de qualificar profissionais, produzir, difundir e democratizar os bens culturais para a primeira infância. Deste modo, colaborar com o desenvolvimento infantil, através da experiência e da educação estética.

\section{REFERÊNCIAS}

BARBOSA, Ana Mae. A imagem no ensino da arte: anos oitenta e novos tempos. 6 . Ed. São Paulo: Perspectiva, 2005. 
DEWEY, John. Arte como experiência. São Paulo: Martins Fontes, 2010.

JAPIASSU, Ricardo. Metodologia do Ensino do Teatro. Campinas: papiros, 2001.

LARROSA, Jorge Bondia. Tremores: escritos sobre experiência. Belo Horizonte: Autêntica Editora, 2014.

MONTAGNER, Hubert. O carinho que ensina (entrevista). Revista Época, 2010.

Disponível em: http://revistaepoca.globo.com/Revista/Epoca/0,„ERT159694-15228-1596943934,00.html. Acesso em 25 de abril de 2016. multidisciplinar. In: CRUZ, S. (Org.). A criança fala: a escuta de crianças em pesquisas. São Paulo: Cortez, 2008.

PONTES, Gilvânia Maurício Dias de. A presença da Arte na Educação Infantil: olhares e intenções. Natal: UFRN, 2011 (Dissertação de Mestrado) 